OPEN ACCESS

Edited by:

Elias Toubi,

Technion Israel Institute of

Technology, Israel

Reviewed by:

Yuval Tal,

Hadassah Medical Center, Israel

Jun Yamagami,

Keio University Hospital, Japan

${ }^{*}$ Correspondence:

Songmei Geng

gsm312@yahoo.com

Specialty section: This article was submitted to

Autoimmune and

Autoinflammatory Disorders,

a section of the journal

Frontiers in Immunology

Received: 31 May 2021 Accepted: 04 August 2021

Published: 24 August 2021

Citation:

Zhou T, Peng B and Geng S (2021)

Emerging Biomarkers and Therapeutic

Strategies for Refractory

Bullous Pemphigoid.

Front. Immunol. 12:718073.

doi: 10.3389/fimmu.2021.718073

\section{Emerging Biomarkers and Therapeutic Strategies for Refractory Bullous Pemphigoid}

\author{
Tong Zhou, Bin Peng and Songmei Geng* \\ Department of Dermatology, The Second Affiliated Hospital, School of Medicine, Xi'an Jiaotong University, Xi'an, China
}

Bullous pemphigoid (BP) is the most common autoimmune subepidermal blistering disorder in the elderly. Systemic and topical use of glucocorticoids and immunosuppressants has been shown to be effective in most patients. However, refractory BP patients are challenged to clinicians with severe clinical symptoms, resistance to treatment, and high relapse rate. How to predict and assess the refractory and severity of bullous pemphigoid is the key issue in clinical practice, and the urgent need for precision medicine in refractory patients is driving the search for biomarkers and biologics. Recently, some biomarkers, such as the level of specific autoantibodies and released cytokines, have been proposed as the potential parameters to reflect the disease severity and predict the treatment response and relapse of refractory BP. Moreover, new biologics targeting pathogenic antibodies, complement, Th2 axis, eosinophils, and Th17 axis have shown potent efficacy on refractory BP. Here, we review the literature and give an overview of emerging biomarkers and therapeutic strategies for refractory bullous pemphigoid to improve the prognosis of the patient.

Keywords: bullous pemphigoid, biomarkers, severity, refractory, relapse, prognosis, biologics

\section{INTRODUCTION}

Bullous pemphigoid (BP) is an uncommon autoimmune subepidermal blistering disease, but accounts for about $70 \%$ of subepidermal bullous diseases, mainly affecting the elderly (1). It is estimated that the annual incidence of BP among different populations in the world is about 12-66 cases per million people (2). The typical clinical features of BP consist tension blisters on erythema or normal skin with intense itching. Histopathology shows subepidermal blisters and inflammatory cell infiltration dominated by eosinophils. Immunologically, IgG and/or C3 are deposited linearly along the basement membrane zone, characterized by the production of autoantibodies against the components of the hemidesmosomes BP180 and BP230 at the dermis-epidermis junction (3).

Genetic predisposing factors, such as HLA-DQ $\beta 11^{*} 0301$ is associated to the occurrence of $\mathrm{BP}, \mathrm{UV}$ exposure, thermal or electrical burns, trauma, drugs, virus infection, and other physical, chemical, and biological factors that are involved in the pathogenesis of susceptible individuals by mediating the loss of immune tolerance to the autoantigen (4). In terms of the pathological mechanism of BP, autoantibodies, immune cells, and inflammatory factors are all involved in the pathogenesis of BP. The interaction of autoantibodies with BP180 brings about the formation of blisters by the activating complement-dependent or independent signals to amplify the inflammatory pathway 
(Figure 1) (5). Non-specific immunosuppressive therapy is effective in most patients. Unfortunately, refractory BP patients are resistant to glucocorticoids or immunosuppressants treatment or have a high relapse rate of $27.87 \%-53 \%$, and most of the relapse occurs in the early stage of remission (within 6 months) (6). Besides, severe adverse reactions due to a long-term use of glucocorticoids or immunosuppressants, including infections, gastrointestinal intolerance, myelosuppression, hepatotoxicity, and even increased risk of cancer could not be ignored (7-9). Hereby, biomarkers for predicting the refractory BP and indicating optimal therapeutic strategies to control their symptoms are urgently required.

With a deep understanding of the pathogenesis of BP, several studies have reported that some parameters involved in the pathogenesis can be used as biomarkers for refractory BP. The purpose of this paper is to analyze the relationship between biomarkers and the disease activity, relapse, and response to treatment. Moreover, the clinical application of new biologics for refractory BP would be reviewed.

\section{EMERGING BIOMARKERS IN BP}

\section{Anti-BP $\lg G$ and $\lg E$}

The reaction of specific autoantibodies produced by autoimmune abnormalities with BP180 is regarded as the central event in the pathogenesis of BP. Both anti-BP180 IgG and IgE could reduce the adhesion of keratinocytes by increasing the internalization of BP180 as well as mediating the recruitment and activation of immune cells through complement-dependent or complement-

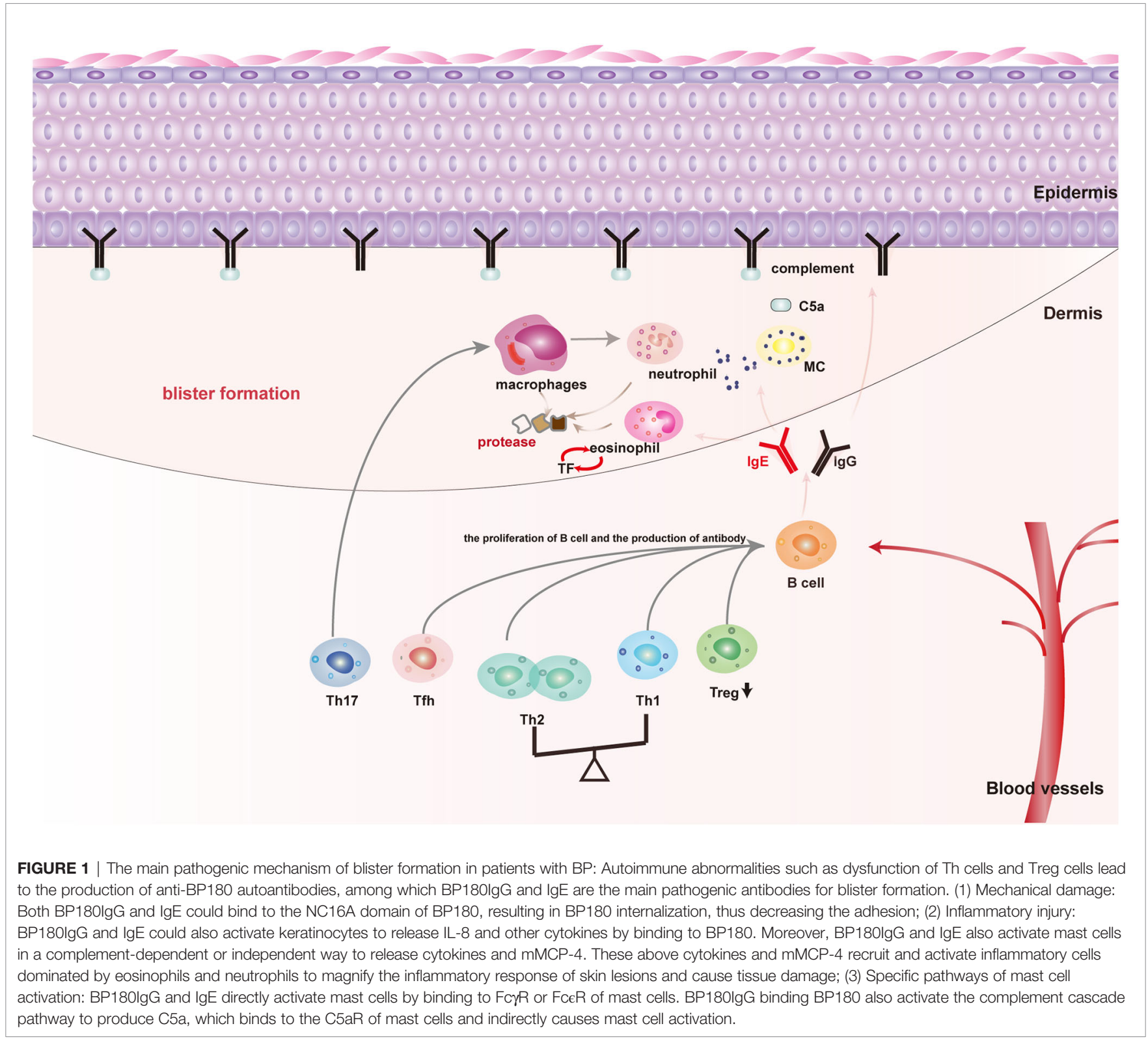


independent pathways to release proteases and cytokines, thus participating in the formation of blisters (5).

\section{BP180 lgG}

BP180 ELISA values and direct immune fluorescence (DIF) are necessary to diagnose BP. The value of anti-BP180NC16A IgG ELISA is positive correlate with the disease severity in crosssectional studies (10-15). The longitudinal follow-up of large samples during traditional treatment suggests that patients with a high level of BP180NC16A IgG indicate refractory BP who have an insufficient response to glucocorticoid and requiring a longer treatment time or a higher dose of glucocorticoid (12, 15-18).

Moreover, BP180IgG levels are of great clinical importance in predicting the risk of relapse. High titer of anti-BP180NC16AIgG $(>27 \mathrm{IU} / \mathrm{mL}$ ) is the only factor independently predicting the relapse of BP within one year after discontinuation of treatment, and the positive predictive value and the negative predictive value are $90.9 \%$ and $51.2 \%$, respectively (19). However, in another study, positive DIF was of a better value than BP180 IgG ELISA values for predicting the relapse risk, with $59.0 \%$ sensitivity, $78.0 \%$ specificity, while $50.0 \%$ positive predictive values and $83.3 \%$ negative predictive value, respectively (20). When the ELISA-BP180 value was high or DIF shows positive, treatment to BP should not be ceased. Relapse is concerned with a slight deceleration of BP180 IgG levels between day 0 and day 60. A high level of BP180 at day $150(23 \mathrm{U} / \mathrm{mL})(21)$ and baseline (53.09 U/mL) could also predict relapse, the sensitivity was $84.2 \%$ and $81.3 \%$, respectively. Meanwhile, the negative reaction to BP180 IgG and BP230 IgG ELISA may be a clue of non-relapse (22).

It should be noted that about $8 \%$ of BP cases have anti-BP230 but not anti-BP180 (BP230-type BP). Most studies showed that anti-BP230IgG levels was not related to disease severity in the presence of BP180 IgG (3). A large proportion of BP230-type cases showed a mild clinical phenotype, which may be related to the weak deposition of IgG1, IgG3, and complement in lesions, indicating the importance of IgG antibody subclass analysis (23). Consistently, as a blocking antibody, it is found that the IgG4 level increased with the improvement of the disease condition, so the change of the main antibody subclass from IgG1 to IgG4 may mean the improvement of the disease (24).

\section{BP180 lgE}

Recently, increasing evidence has shown that $\operatorname{IgE}$ is involved in the occurrence of $\mathrm{BP}$, but contradictions are still in the relationship between IgE and disease severity, which may be due to the lack of a unified method for the quantitative detection of BP180IgE (3). Elevated IgE levels have been reported in $22 \%-$ $100 \%$ of patients with BP (25). A few studies reported that the circulating level of BP180NC16A IgE in patients was not related to the severity of the disease (26-28). For example, Ma et al. believed that high titers of anti-BP180 IgG contributes mostly to the disease activity than the anti-BP180 IgE level in patients (28). However, since previous studies have verified the pathogenic effect of BP180IgE in cell culture and animal models, Omalizumab targeting IgE has been successfully used in patients with refractory $\mathrm{BP}$ (3). It agrees with the conclusion that high levels of circulating BP180NC16A IgE and total IgE in serum are correlated with higher BPDAI scores of BP patients $(11,13,25,29-32)$. It is an urgent need to explore and unify BP180 IgE detection methods with acceptable sensitivity and specificity to confirm this conclusion. On the other hand, as a low-affinity Fc receptor of IgE, the levels of CD23 in tissue or and sCD23 in serum are consistent with the severity of the disease (33-35), which also imply that IgE is another key participant in the pathogenesis of BP. In addition, based on the existence of high levels of anti-BP180IgG antibodies, the appearance of antiBP180IgE supports that those patients need more active therapies for remission (31). The patients with a high level of anti-BP180 IgG need to jointly evaluate the level of anti-BP180 $\mathrm{IgE}$ in a subsequent treatment to more effectively identify refractory BP patients. Not only that, when the total serum IgE level remains high and the skin lesions could not be effectively controlled, Omalizumab can be considered (13, 36-38).

\section{Chemokines}

All infiltrating cells contribute to the pathogenesis of BP. Especially, the chemotaxis and activation of major effector cells such as eosinophils, neutrophils, and monocytes/macrophages in the lesions, directly leading to the blister formation through the release of proteases and cytokines (39). Chemotactic factors that attract inflammatory cells infiltrating should be attended to.

CXCL8 (IL-8), a neutrophil-attracting chemokine, in serum and blister fluid (BF) of patients could change with the fluctuation of the disease activity (40-42). CXCL9(MIG), CXCL10 (IP10), and Th2 chemokine, such as CCL2 (MCP-1), CCL17 (TARC), CCL18 (PARC), and CCL22 (MDC) cannot only attract $\mathrm{T}$ lymphocytes and monocytes to the lesion but also relate to the disease severity (43-48). In addition, elevated serum CXCL9 levels only occur in patients with a serious condition, and should be particularly vigilant against the disease deterioration $(44,47)$. CXCL10 induces monocytes and neutrophils to express MMP-9, which is involved in the relapse of BP. The serum CXCL10 levels can be upregulated by IL-17 and continue to rise or maintain high levels at 60 days or within the first year after treatment in relapse patients, which maintain and amplify the inflammatory response (49). What is more, CCL17 levels sharply reflect the disease activity with a higher sensitivity than BP180NC16A IgG, and could be viewed as a promising biomarker for predicting the early relapse of the disease (43).

Cytokines such as IL-5, CCL5 (RANTES), CCL11 (Eotaxin), and CCL26 (Eotaxin3) are involved in the proliferation and recruitment of eosinophils from the peripheral circulation to the lesions, and their levels always keep in line with the number of blisters (40, 44, 50-52). Particularly, IL-5 is the promising biomarker for disease severity, as IL-5 levels in serum and BF could reflect the disease severity in several different population studies. The count of peripheral blood eosinophils fluctuates in line with the disease severity in BP $(30,32,53-58)$.

\section{Cytokines}

Inflammatory mediators, for instance, IL- $1 \beta$, IL-6, and TNF- $\alpha$, reflecting the disease severity, because serum levels of TNF- $\alpha$, 
IL- 6 and blister contents of IL- $1 \beta$ and TNF- $\alpha$ are significantly higher in severe patients than in mild patients. But they are not specific enough for BP, because they rise in many other conditions $(40-42,59)$. In contrast, patients with severe clinical manifestations and treatment resistance are often accompanied by low levels of IL-10 secreted by Treg, and the increasing levels of IL-10 is related to clinical improvement in BP (60-62). These observations support the idea that a persistent immune activation exists in diseases that are relatively or absolutely deficient in IL-10, and the recovery of relatively defective Treg and IL-10 is helpful to alleviate the disease.

Moreover, some members of the TNF family, such as sCD40L, a proliferation-inducing ligand (APRIL), and B lymphocyte activating factor (BAFF), contribute to B cell proliferation and autoantibodies production, they are more sensitive than autoantibodies to reflect the treatment response and early relapse. They often occur before the appearance of skin lesions and the increase of BP180NC16A antibody levels, and decline after treatment, so that detection of their serum levels could distinguish the tendency of relapse in time (63-65). Likewise, IL-18, as well as IL-15 derived from macrophages and IL-21 secreted by Tfh cell increase in BF or serum of BP, which promote the proliferation of $\mathrm{B}$ cells and the production of antibodies, also correlate with the disease activity (42, 66-68).

In $\mathrm{BP}$ patients with a continuous remission and relapse in the first year of treatment, serum autoantibodies titers, as well as concentrations of cytokines belonging to the Th17 axis are different. IL-17 and IL-23 participate in a variety of pathophysiological mechanisms of relapse. To begin with, both IL-17 and IL-23 independently induce DNA extracellular traps (ETs) formation in patients with relapse; subsequently, they also stimulate monocytes and neutrophils to produce MMP-9, which contributes to the separation of the dermis and epidermis; eventually, they upregulate the expression of glucocorticoid receptor- $\beta$ related to the resistance to glucocorticoid therapy $(69,70)$. During the one-year follow-up, Plee et al. found that the patients with a significantly decreased IL17 level within 0-60 days showed a continuous remission, while the patients whose IL-17 level remained high within 60 days after treatment had a higher risk of relapse. Similarly, patients with significantly elevated IL-23 and MMP-9 levels within 0-60 days were also prone to relapse (69).

However, we have doubts about the predictive value of serum inflammatory mediator levels not only because a variety of factors influence the inflammatory mediator levels in serum and make them unrepresentative of the levels in tissues, but because the dynamic monitoring of serum inflammatory mediator levels is costly.

\section{Eosinophil and Eosinophil Cationic Protein}

Eosinophils, as the main infiltration cell in the lesions of BP, play the central effect on blister formation and pruritus by secreting protease and cytokines like Eosinophil cationic protein (ECP) and IL-31 (3), it also provides several biomarkers to reflect disease severity and relapse.

ECP in BF released by eosinophils contributed to the blister formation, which keeps in line with $\mathrm{BP}$ severity $(51,58,71,72)$.
Giusti et al. also found that the serum concentration of ECP decreased within 0-60 days after treatment, but it did not decrease in patients with subsequent relapse. The cutoff value for the decrease of ECP concentration from baseline to 60 days was $12.8 \mathrm{ng} / \mathrm{mL}$, the sensitivity, specificity, positive predictive value, and negative predictive value for judging the clinical remission of BP were $63.2 \%, 64.3 \%, 81.1 \%$, and $41.8 \%$, respectively (72).

Eosinophils are known to initiate the coagulation cascade at skin level via $\mathrm{TF}$, which in $\mathrm{BP}$ promotes the recruitment of eosinophils in skin lesions and the expression of matrix metalloproteinases (MMP)-9, making the coagulation cascade become an auxiliary mechanism that is involved in blister formation. Moreover, serum and BF levels of F1+2 and Ddimer ascend in patients with a more severe disease and significantly descend with the remission of the disease $(57,58$, 73). The detection of $\mathrm{D}$-dimer has increased the diagnostic evidence of chronic urticaria in clinics (74). After excluding the influence of other diseases, the indicative effect of $\mathrm{D}$-dimer on refractory BP is worth further exploring.

\section{Others}

Several experimental studies have proved the contribution of the classical pathway of a complement cascade to the formation of BP blisters, C5a produced by complement cascade could recruit and activate mast cells to initiate a downstream inflammatory cascade reaction (75). The deposition of autoantibodies and complement C3 along the dermis-epidermis junction is the diagnostic criteria of BP. Interestingly, a more abnormal complement activation is present in more active patients. The complement-fixation assay is a simple method to detect the complement activation by autoantibodies in vitro, which could reflect the BP activity (76). Due to the maturity and simplicity of this clinical assay, a larger sample of clinical trial will be necessary.

On the other hand, the activation of mast cells in the lesions is the earliest event in the formation of BP blister. It cannot only secrete inflammatory cytokines to promote subsequent infiltration of inflammatory cells such as neutrophils in skin lesions, but also release mast cell protease (MCP)- 4 to activate major proteases such as MMP-9 that cause BP tissue damage (77). Trypsin in serum and BF, as reliable indicators of mast cell activation, seems to be consistent with the disease activity (78, 79), but more research is required to obtain a high-level evidence.

Modern techniques such as RNA sequencing help identify potential BP biomarkers. MiR-1291 is an endogenous noncoding RNA, which is also a possible biomarker of some autoimmune disorders. A recent study has found that MiR1291 significantly increase in active patients, and the serum relative expression could reflect the $\mathrm{BP}$ activity, the sensitivity and specificity were $75.56 \%$ and $81.03 \%$, respectively (80). The implementation of these techniques may not only help to find more potential biomarkers of diseases but also improve our understanding of the pathogenesis of BP. Some clinical characters are also linked to relevant aspects of the BP. At baseline, patients with generalized diseases and neurological diseases such as dementia have a higher risk of relapse (21). 
It is necessary to assess whether the patients have neurological diseases or a wide range of disease areas as soon as possible to take more positive and reasonable measures.

In summary, both innate immunity and adaptive immunity play important roles in the pathogenesis of BP. Although a large number of laboratory parameters are related to refractory $\mathrm{BP}$, we recommend that especially anti-BP180 NC16A IgG, anti-BP180 NC16A IgE, total IgE, the count of peripheral blood eosinophils, ECP, D-dimer, F1+2, IL-5,CXCL-8, CCL17, and IL-10 are the most promising indicators for severity, based on clinical relevance, repeatability (i.e., more than three studies from different centers showing the same correlation), and feasibility, and their value as biomarkers of disease severity deserves further investigation. Some potential markers such as IL-1 $\beta$, IL-6, TNF$\alpha$, etc. are not specific enough, so they should be interpreted more carefully. However, due to the small number of large-scale studies on biomarkers for treatment resistance or relapse, the level of evidence is still very low, and more research is needed. Having said that, several large-scale studies have provided evidence of the clinical efficacy of biomarkers reflecting the risk of disease relapse or treatment resistance. Detecting BP180NC16AIgG antibody levels at baseline, serum levels of IL17, IL-23, CXCL10, CCL17, BAFF, APRIL, sCD40L, MMP-9, and ECP during treatment, and DIF or BP180NC16A IgG ELISA on the day ready to stop the treatment may help clinicians to identify the patients who are prone to relapse and take more active treatment and management measures to reduce the possibility of relapse., but it should be clear that complex autoantibody and cytokine disorders exist in BP, and it is often not accurate to use a biomarker alone. More large-scale clinical research is needed to explore new biomarkers or verify promising biomarkers that have been found, and the joint detection of these biomarkers is more meaningful to reflect the disease status.

\section{EMERGING BIOLOGICS FOR BP}

Currently, no biologics have been approved for BP, and the treatment mainly depends on traditional immunosuppressive therapies. However, high-dose of glucocorticoids and immunosuppressants cause obvious side effects, and are associated with a high relapse rate, precision medicine of refractory $\mathrm{BP}$ attracts much attention. With the emergence of biomarkers, more and more biologics targeting the pathogenic mechanism are entering the experimental stage or being used in the treatment of refractory BP in the clinic. We will focus on these biologics.

\section{Biologics Targeting Pathogenic Antibodies}

Pathogenic antibodies including BP180IgG and IgE are used as tools to identify refractory $\mathrm{BP}$, and in some case reports, biologics specifically targeting them have shown great advantages in managing refractory $\mathrm{BP}$.

\section{Rituximab}

Rituximab is a monoclonal antibody targeting the specific CD20 transmembrane glycoprotein of mature B cells. It causes B cell depletion and antibodies reduction through antibody-dependent cytotoxicity (ADCC), complement-dependent cytotoxicity (CDC), and direct induction of apoptosis. Rituximab was originally used for non-Hodgkin's lymphoma and has been recommended by the international panel of experts for the first-line treatment of pemphigus $(81,82)$.

In recent times, Rituximab has been gradually applied to refractory BP. First-line combination therapy with rituximab and corticosteroids could significantly improve the complete remission rate of patients on the basis of reducing the dose of prednisone and not increasing the incidence of adverse reactions. Now, the dose of Rituximab for BP treatment has not been specified, almost all clinical applications use the recommended dose for non-Hodgkin's lymphoma or rheumatoid arthritis, that is, intravenous infusion of Rituximab $375 \mathrm{mg} / \mathrm{m}^{2}$ per week for four weeks or 1,000 mg per week for two consecutive weeks (83).

It is worth noting the relapse and adverse reactions under the treatment of Rituximab. CD20 is not expressed on long-living antibody-producing plasma cells, even the peripheral blood B cells achieve complete consumption and the autoantibodies disappear, patients could only achieve temporary and partial remission, so it is very important to observe the tendency of relapse and to find a suitable maintenance treatment (84). Low peak BAFF levels and the increased proportion of memory B cells before B-cell recovery are helpful to identify BP patients who are prone to relapse or resistant to Rituximab (85). In addition, infusion-related adverse reactions are common and serious adverse events are rare, there are occasional neutropenia, skin toxicity (leukoclastic vasculitis and Stevens-Johnson syndrome, etc.), systemic infection, and even death (86-88). IVIg combined with Rituximab in the treatment of refractory BP could help patients to rebuild the immunomodulatory function to reduce the incidence of adverse events and achieve lasting remission (89). As a steroid protective agent, Rituximab has benefited some patients with refractory BP and brought a higher remission rate, but it is necessary to monitor the hemogram, blood pressure, and temperature, and take care of the infection and infusion-related adverse reactions.

\section{Omalizumab}

As the first targeted drug approved by the FDA for the treatment of chronic urticaria (74), Omalizumab was successfully cured a patient with refractory BP for the first time in 2009 (90), because it could prevent IgE from interacting with FceR I on mast cells and other effector cells to reduce the release of inflammatory mediators by binding to the $\mathrm{Fc}$ region of free $\mathrm{IgE}$, downregulating of FceR I expression and dissociating the IgE- FceR I complex.

A total of 16 studies have reported the efficacy of Omalizumab in the treatment of refractory BP. In these studies, most patients showed elevated total IgE and eosinophil levels and resistance to immunosuppressive therapy, that is, intractable pruritus or extensive skin lesions were difficult to control, or had complications such as osteoporosis and infections. After they were treated with Omalizumab, their itching, new blisters, and eosinophil count were significantly improved at the earliest within a week, the lesions basically disappeared, and the dose of glucocorticoid gradually decreased after an average of 3 months. Most patients could benefit from subcutaneous injection of $300 \mathrm{mg}$ 
Omalizumab every 4 weeks as a steroid protective agent or monotherapy, with varying maintenance time (up to 18 months), and no serious adverse reactions $(36,38,90-102)$. In the absence of large-scale clinical trials, the recommended dose of Omalizumab is based on its use in asthma or chronic urticaria. During the period of treatment, peripheral blood eosinophil counts and FceR I have been linked to response to Omalizumab, and followed the disease activity. Patients with a continuous downregulation of Fce RI expression and eosinophil count are more likely to show a satisfactory response to Omalizumab $(38,99)$.

In the current case reports, the conclusions about Omalizumab and Rituximab for refractory BP are encouraging, but their efficacy and safety have not been tested in clinical trials, which is essential for eliminating bias and determining their options in the treatment of BP. Recently, an open-label, single group design, phase 3 clinical trial evaluating the efficacy and safety of Rituximab combined with Omalizumab in the treatment of BP is underway (NCT04128176).

\section{Biologics Targeting Complements}

Complement cascade reaction is involved in BP blister formation, biologics specifically blocking it may be beneficial to the treatment of BP.

\section{BIVV009}

BIVV009 (sutimlimab) is a humanized IgG4 monoclonal antibody, and specifically inhibits the first components subcomponent $(\mathrm{C} 1 \mathrm{~s})$ of the complement system to interfere with the classical pathway of complement cascade. The safety and activity of BIVV009 for the treatment of BP have been tested in phase 1 clinical trial (NCT02502903) involving 10 active BP subjects. The results showed that $60 \mathrm{mg} / \mathrm{kg}$ infusion of BIVV009 four times a week was enough to inhibit the classical complement pathway as well as safe and tolerable in this elderly population. Only mild to moderate adverse events such as headache and fatigue were reported (103).

Given the success of phase I trials, FDA designated BIVV009 as an orphan drug of BP in August 2017, thus promoting future clinical development (75). A prospective, randomized, doubleblind, placebo-controlled phase 1 clinical trial (NCT02502903) with a larger sample continues.

\section{Avdoralimab}

Avdoralimab is a specific antibody against C5aR1, which is safe for the treatment of solid tumors and rheumatoid arthritis. Karsten et al. have previously demonstrated that C5aR1 mediates the antiBP180 IgG-induced pathogenicity, while C5aR2 has a protective effect (104). Therefore, more specific blocking of the C5a-C5aR1 axis by Avdoralimab is expected to be used in the treatment of BP. Therefore, $40 \mathrm{BP}$ patients are expected to participate in an openlabel, multicenter, randomized, parallel-group phase 2 clinical trial (NCT04563923).

\section{Biologics Targeting Th2 Axis}

Dupilumab, a monoclonal antibody against IL-4R $\alpha$, not only blocks the signal transduction mediated by IL-4 and IL-13, but also inhibits the secretion of IL-31 by eosinophils (101). It has been approved for the treatment of atopic dermatitis and chronic rhinosinusitis with moderate to severe asthma and nasal polyposis. In most patients with $\mathrm{BP}$, the frequency of cells producing IL-4 and IL-13 in blood and lesions increases, and decreases as the disease improves. Dupilumab is also an effective inhibitor of Th2-related chemokines CCL17, CCL18, CCL22, and CCL26, which fluctuate synchronously with the disease severity. Therefore, Dupilumab could specifically block the pathogenic effects of these cytokines in BP (105). Recently, Dupilumab has been successfully used in refractory BP, especially for the relief of intractable itching (106).

In 2018, Dupilumab monotherapy successfully treated a patient with refractory BP for the first time (105). It also relieves that itching could not be controlled by Omalizumab in the treatment of BP (101). Abdat et al. reported the study with the largest sample. A total of 13 patients with refractory BP initially accepted the approved administration regimen for atopic dermatitis, that is, Dupilumab $600 \mathrm{mg}$ was injected subcutaneously for the first time, and then 300 mg was injected subcutaneously every two weeks, but some patients could only achieve partial control of the disease, so the frequency of medication was mostly changed to once a week. Six of them received Dupilumab monotherapy, seven patients received a combination of glucocorticoid or methotrexate with Dupilumab for an average of 5 months. A total of $84.6 \%$ of the patients achieved remission of the disease, and there was no obvious adverse effect. Although $53.8 \%$ of the patients were cleared of the disease, $42.9 \%$ of them received Dupilumab more frequently than every two weeks. Wherein, the weekly frequency of treatment seems to be more conducive to remission (107).

Currently, a multicenter, randomized, double-blind, parallelgroup, placebo-controlled clinical trial (NCT04206553) is in progress to evaluate the efficacy and safety of Dupilumab in adult patients with BP.

\section{Biologics Targeting Eosinophils}

As the main infiltrating cells of BP lesions and the main effector cells of blisters formation, eosinophils are involved in the pathogenesis of $\mathrm{BP}$ in many ways, and provide several biomarkers indicating the severity and refractory of BP. Targeting eosinophils is a candidate therapeutic strategy for BP.

\section{Bertilimumab}

Bertilimumab is a completely human monoclonal antibody targeting eotaxin-1 (CCL-11), while eotaxin-1 is mainly involved in the recruitment of eosinophils from the peripheral circulation to the skin lesion in BP. The use of Bertilimumab is designed to reduce eosinophil infiltration in BP lesions. An open, single-group, phase 2 clinical trial (NCT02226146) has been conducted to study the safety, efficacy, and pharmacodynamics of Bertilimumab in patients with newly diagnosed moderate to generalized bullous pemphigoid. The study included nine subjects with moderate to severe BP who were treated with Bertilimumab as a steroid protector for four weeks. Bertilimumab was well tolerated in all nine subjects. The BPDAI score decreased by $81 \%$, and no serious drug-related adverse events were reported. Based on these results, FDA has granted an orphan drug designation to Bertilimumab in $\mathrm{BP}$. 


\section{Benralizumab}

Benralizumab is a humanized IgG1 $\kappa$ monoclonal antibody against the IL-5R $\alpha$ subunit, which acts by blocking the downstream signaling of IL-5. It induces target cell killing mediated by NK cells through ADCC, which leads to the decrease of eosinophils and basophils in circulation. Considering the pathogenic role of IL-5 and eosinophils in BP, a multi-country, randomized, double-blind, parallel-group, placebo-controlled phase 3 clinical trial (NCT04612790) has just begun to investigate the effectiveness of Benralizumab for BP.

\section{Biologics Targeting Th17 Axis}

Th17 axis takes part in the blister formation and drug resistance in BP relapse. The patients who are prone to relapse may be the indications for biologics targeting it.

\section{Ustekinumab}

Ustekinumab is a humanized monoclonal antibody targeting the p40 subunit shared between IL-23 and IL-12. IL-23 often has a synergistic effect with IL-17 in BP relapse (108). To study the efficacy and safety of Ustekinumab combined with super-effective topical corticosteroids in the treatment of BP, an open-label, single-group design phase 2 clinical trial is in progress (NCT04117932).

\section{Tildrakizumab}

Tildrakizumab is an IL-23 inhibitor that specifically inhibits the p19 subunit of IL-23, thereby reducing its activity. It has been approved for the treatment of adult plaque psoriasis by the FDA (109). Recently, an open-label, single-group design phase 1 clinical trial (NCT04465292) has been conducted to evaluate the efficacy of Tildrakizumab for BP.

Obviously, biologics are promising therapeutic options for patients who are resistant to standard therapy. Rituximab, Omalizumab, and Dupilumab have been successfully used in clinic, and clinical trials of new biologics targeting different mechanisms have been gradually carried out. Furthermore, for the elderly with a high incidence of $\mathrm{BP}$, it is prone to have contraindications of glucocorticoid and immunosuppressive, such as hypertension, arteriosclerosis, diabetes, osteoporosis, and cardiorenal insufficiency, and chronic recurrent course requires long-term and high-dose use of glucocorticoid, which increases the risk of adverse events. Although the local use of glucocorticoids is considered to be relatively safe, it is indeed difficult to implement for extensive lesions. For these patients, appropriate biologics should be available as a first-line therapy regimen by comprehensively evaluating the basic condition, so as to bring better prognosis for patients.

\section{REFERENCES}

1. Joly P, Baricault S, Sparsa A, Bernard P, Bédane C, Duvert-Lehembre S, et al. Incidence and Mortality of Bullous Pemphigoid in France. J Invest Dermatol (2012) 132:1998-2004. doi: 10.1038/jid.2012.35

2. Zhao CY, Murrell DF. Outcome Measures for Autoimmune Blistering Diseases. J Dermatol (2015) 42:31-6. doi: 10.1111/1346-8138.12711

3. Messingham KN, Crowe TP, Fairley JA. The Intersection of IgE Autoantibodies and Eosinophilia in the Pathogenesis of Bullous

\section{Markers for Prognosis}

The mortality rate of BP patients one year after diagnosis is $9.3 \%-$ $41 \%$ (110). Clinical features and biomarkers of patients that indicate the risk of death have been gradually discovered. Individual factors, such as advanced age, low Karnofsky score $(\leq 40)$, comorbidity groups of the nervous system (including Parkinson's syndrome, dementia, and stroke), chronic basic diseases (such as heart failure and chronic kidney disease), and iatrogenic factors including longterm hospitalization and high-dose corticosteroids alone are associated with the increased risk of death. On the contrary, Statins and topical glucocorticoids or low-dose glucocorticoids combined with immunomodulators are protective factors associated with a reduced risk of death (9, 26, 110-116). Moreover, there are a few studies on biomarkers related to the risk of death. High levels of anti-BP180 autoantibodies $(\geq 61 \mathrm{U} / \mathrm{mL})$ at diagnosis have to do with an increased risk of death $(26,110)$. High erythrocyte sedimentation rate (ESR) and low serum albumin levels are also correlated with the risk of death in BP, but they could not be used as special biomarkers to predict the prognosis of BP, because they are easily influenced by other disorders (115). During treatment, more attention should be paid to the above signals indicating poor prognosis in order to better manage refractory BP.

\section{CONCLUSION}

Although there is increasing interest in finding reliable indicators for different aspects of BP, the level of evidence supporting existing biomarkers is still very low. We advocate researchers to conduct large-scale multicenter clinical trials as much as possible, and actively explore better detection methods to identify or confirm potential biomarkers. For refractory BP patients indicated by clinical manifestations or biomarkers and elderly patients with severe adverse reactions to high-dose glucocorticoids, biologics becomes the promising treatment, some of them have been of benefit to refractory BP patients. More randomized controlled trials are needed to determine their efficacy, safety, and availability for the treatment of patients with BP. All in all, monitoring and targeting these meaningful factors will play an important role in the management of refractory BP.

\section{AUTHOR CONTRIBUTIONS}

TZ, BP, and SG conceived this paper. TZ wrote this manuscript. All authors contributed to the article and approved the submitted version.

Pemphigoid. Front Immunol (2019) 10:2331. doi: 10.3389/fimmu. 2019.02331

4. Lo Schiavo A, Ruocco E, Brancaccio G, Caccavale S, Ruocco V, Wolf R. Bullous Pemphigoid: Etiology, Pathogenesis, and Inducing Factors: Facts and Controversies. Clin Dermatol (2013) 31:391-9. doi: 10.1016/ j.clindermatol.2013.01.006

5. Liu Y, Li L, Xia Y. BP180 Is Critical in the Autoimmunity of Bullous Pemphigoid. Front Immunol (2017) 8:1752. doi: 10.3389/fimmu 2017.01752 
6. Wang Y, Mao X, Wang Y, Zeng Y, Liu Y, Jin H, et al. Relapse of Bullous Pemphigoid: An Update on This Stubborn Clinical Problem. Ann Med (2018) 50:234-9. doi: 10.1080/07853890.2018.1443346

7. Binois R, Nadal M, Esteve E, De Muret A, Kerdraon R, Gheit T, et al. Cutaneous Kaposi Sarcoma During Treatment With Superpotent Topical Steroids and Methotrexate for Bullous Pemphigoid: Three Cases. Eur J Dermatol (2017) 27:369-74. doi: 10.1684/ejd.2017.3027

8. Gual A, Iranzo P, Mascaró JM Jr. Treatment of Bullous Pemphigoid With Low-Dose Oral Cyclophosphamide: A Case Series of 20 Patients. J Eur Acad Dermatol Venereol (2014) 28:814-8. doi: 10.1111/jdv.12155

9. Kalinska-Bienias A, Lukowska-Smorawska K, Jagielski P, Kowalewski C, Wozniak K. Mortality in Bullous Pemphigoid and Prognostic Factors in 1st and 3rd Year of Follow-Up in Specialized Centre in Poland. Arch Dermatol Res (2017) 309:709-19. doi: 10.1007/s00403-017-1772-x

10. Daneshpazhooh M, Ghiasi M, Lajevardi V, Nasiri N, Balighi K, Teimourpour A, et al. BPDAI and ABSIS Correlate With Serum AntiBP180 NC16A IgG But Not With Anti-BP230 IgG in Patients With Bullous Pemphigoid. Arch Dermatol Res (2018) 310:255-9. doi: 10.1007/s00403018-1817-9

11. Döpp R, Schmidt E, Chimanovitch I, Leverkus M, Bröcker EB, Zillikens D. IgG4 and IgE Are the Major Immunoglobulins Targeting the NC16A Domain of BP180 in Bullous Pemphigoid: Serum Levels of These Immunoglobulins Reflect Disease Activity. J Am Acad Dermatol (2000) 42:577-83. doi: $10.1067 / \mathrm{mjd} .2000 .103986$

12. Feng $\mathrm{S}, \mathrm{Wu} \mathrm{Q}$, Jin $\mathrm{P}$, Lin L, Zhou W, Sang H, et al. Serum Levels of Autoantibodies to BP180 Correlate With Disease Activity in Patients With Bullous Pemphigoid. Int J Dermatol (2008) 47:225-8. doi: 10.1111/j.13654632.2008.03473.x

13. Kalowska M, Ciepiela O, Kowalewski C, Demkow U, Schwartz RA, Wozniak K. Enzyme-Linked Immunoassay Index for Anti-NC16a IgG and IgE Auto-Antibodies Correlates With Severity and Activity of Bullous Pemphigoid. Acta Derm Venereol (2016) 96:191-6. doi: 10.2340/ 00015555-2101

14. Pomponi D, Di Zenzo G, Zennaro D, Calabresi V, Eming R, Zuzzi S, et al. Detection of IgG and IgE Reactivity to BP180 Using the ISAC ${ }^{\circledR}$ Microarray System. Br J Dermatol (2013) 168:1205-14. doi: 10.1111/bjd.12161

15. Zhou XP, Liu B, Xu Q, Yang Y, He CX, Zuo YG, et al. Serum Levels of Immunoglobulins G1 and G4 Targeting the Non-Collagenous $16 \mathrm{~A}$ Domain of BP180 Reflect Bullous Pemphigoid Activity and Predict Bad Prognosis. J Dermatol (2016) 43:141-8. doi: 10.1111/1346-8138.13051

16. Amo Y, Ohkawa T, Tatsuta M, Hamada Y, Fujimura T, Katsuoka K, et al. Clinical Significance of Enzyme-Linked Immunosorbent Assay for the Detection of Circulating Anti-BP180 Autoantibodies in Patients With Bullous Pemphigoid. J Dermatol Sci (2001) 26:14-8. doi: 10.1016/s09231811(00)00149-3

17. Kobayashi M, Amagai M, Kuroda-Kinoshita K, Hashimoto T, Shirakata Y, Hashimoto K, et al. BP180 ELISA Using Bacterial Recombinant NC16a Protein as a Diagnostic and Monitoring Tool for Bullous Pemphigoid. J Dermatol Sci (2002) 30:224-32. doi: 10.1016/s0923-1811(02)00109-3

18. Schmidt E, Obe K, Bröcker EB, Zillikens D. Serum Levels of Autoantibodies to BP180 Correlate With Disease Activity in Patients With Bullous Pemphigoid. Arch Dermatol (2000) 136:174-8. doi: 10.1001/archderm. 136.2.174

19. Bernard P, Reguiai Z, Tancrède-Bohin E, Cordel N, Plantin P, Pauwels C, et al. Risk Factors for Relapse in Patients With Bullous Pemphigoid in Clinical Remission: A Multicenter, Prospective, Cohort Study. Arch Dermatol (2009) 145:537-42. doi: 10.1001/archdermatol.2009.53

20. Ingen-Housz-Oro S, Plée J, Belmondo T, Maizières $M$, Pham BN, Hüe $S$, et al. Positive Direct Immunofluorescence Is of Better Value Than ELISABP180 and ELISA-BP230 Values for the Prediction of Relapse After Treatment Cessation in Bullous Pemphigoid: A Retrospective Study of 97 Patients. Dermatology (2015) 231:50-5. doi: 10.1159/000381143

21. Fichel F, Barbe C, Joly P, Bedane C, Vabres P, Truchetet F, et al. Clinical and Immunologic Factors Associated With Bullous Pemphigoid Relapse During the First Year of Treatment: A Multicenter, Prospective Study. JAMA Dermatol (2014) 150:25-33. doi: 10.1001/jamadermatol.2013.5757

22. Koga H, Teye K, Ishii N, Ohata C, Nakama T. High Index Values of EnzymeLinked Immunosorbent Assay for BP180 at Baseline Predict Relapse in
Patients With Bullous Pemphigoid. Front Med (Lausanne) (2018) 5:139. doi: $10.3389 /$ fmed.2018.00139

23. Zheng $\mathrm{M}$, Ujiie $\mathrm{H}$, Iwata $\mathrm{H}$, Muramatsu $\mathrm{K}$, Yoshimoto $\mathrm{N}$, Ito $\mathrm{T}$, et al. Characteristics of IgG Subclasses and Complement Deposition in BP230Type Bullous Pemphigoid. J Eur Acad Dermatol Venereol (2019) 33:595-600. doi: $10.1111 /$ jdv. 15325

24. Modre B, Allen J, Wojnarowska F. Does Class Switching Contribute to Remission in Bullous Pemphigoid? Acta Derm Venereol (1999) 79:127-31. doi: $10.1080 / 000155599750011345$

25. Hashimoto T, Ohzono A, Teye K, Numata S, Hiroyasu S, Tsuruta D, et al. Detection of IgE Autoantibodies to BP180 and BP230 and Their Relationship to Clinical Features in Bullous Pemphigoid. $\mathrm{Br} J$ Dermatol (2017) 177:141-51. doi: 10.1111/bjd.15114

26. Holtsche MM, Goletz S, van Beek N, Zillikens D, Benoit S, Harman K, et al. Prospective Study in Bullous Pemphigoid: Association of High Serum AntiBP180 IgG Levels With Increased Mortality and Reduced Karnofsky Score. Br J Dermatol (2018) 179:918-24. doi: 10.1111/bjd.16553

27. Kamata A, Kurihara Y, Funakoshi T, Takahashi H, Kuroda K, Hachiya T, et al. Basement Membrane Zone IgE Deposition Is Associated With Bullous Pemphigoid Disease Severity and Treatment Results. Br J Dermatol (2020) 182:1221-7. doi: 10.1111/bjd.18364

28. Ma L, Wang M, Wang X, Chen X, Zhu X. Circulating IgE Anti-BP180 Autoantibody and Its Correlation to Clinical and Laboratorial Aspects in Bullous Pemphigoid Patients. J Dermatol Sci (2015) 78:76-7. doi: 10.1016/ j.jdermsci.2015.02.015

29. Cho YT, Liao SL, Wang LF, Chu CY. High Serum Anti-BP180 IgE Levels Correlate to Prominent Urticarial Lesions in Patients With Bullous Pemphigoid. J Dermatol Sci (2016) 83:78-80. doi: 10.1016/j.jdermsci. 2016.03.009

30. Delli FS, Sotiriou E, Lazaridou E, Apalla Z, Lallas A, Vakirlis E, et al. Total IgE, Eosinophils, and Interleukins 16, 17A, and 23 Correlations in Severe Bullous Pemphigoid and Treatment Implications. Dermatol Ther (2020) 33: e13958. doi: 10.1111/dth.13958

31. Iwata $\mathrm{Y}$, Komura $\mathrm{K}$, Kodera $\mathrm{M}$, Usuda $\mathrm{T}$, Yokoyama $\mathrm{Y}$, Hara $\mathrm{T}$, et al. Correlation of IgE Autoantibody to BP180 With a Severe Form of Bullous Pemphigoid. Arch Dermatol (2008) 144:41-8. doi: 10.1001/archdermatol. 2007.9

32. van Beek N, Lüttmann N, Huebner F, Recke A, Karl I, Schulze FS, et al. Correlation of Serum Levels of IgE Autoantibodies Against BP180 With Bullous Pemphigoid Disease Activity. JAMA Dermatol (2017) 153:30-8. doi: 10.1001/jamadermatol.2016.3357

33. Furukawa F, Kumagai S, Sakamoto Y, Takigawa M, Imamura S. Elevated Serum Levels of IgE-Binding Factor/Soluble CD23 in Bullous Pemphigoid. J Dermatol Sci (1994) 7:150-4. doi: 10.1016/0923-1811 (94)90089-2

34. Maekawa N, Hosokawa H, Soh H, Kasahara M, Izumi H, Yodoi J, et al. Serum Levels of Soluble CD23 in Patients With Bullous Pemphigoid. J Dermatol (1995) 22:310-5. doi: 10.1111/j.1346-8138.1995.tb03394.x

35. Inaoki M, Sato S, Takehara K. Elevated Expression of CD23 on Peripheral Blood B Lymphocytes From Patients With Bullous Pemphigoid: Correlation With Increased Serum IgE. J Dermatol Sci (2004) 35:53-9. doi: 10.1016/ j.jdermsci.2004.03.009

36. James T, Salman S, Stevenson B, Bundell C, Kelly G, Nolan D, et al. IgE Blockade in Autoimmunity: Omalizumab Induced Remission of Bullous Pemphigoid. Clin Immunol (2019) 198:54-6. doi: 10.1016/j.clim. 2018.12.015

37. Kwon HJ, Ahn GR, Choi SY, Li K, Seo SJ. Explosive Bullous Pemphigoid With High Serum Total IgE: Serum IgE as a Biomarker That Reflects Disease Activity. JAAD Case Rep (2018) 4:352-4. doi: 10.1016/j.jdcr. 2017.09.011

38. Yu KK, Crew AB, Messingham KA, Fairley JA, Woodley DT. Omalizumab Therapy for Bullous Pemphigoid. J Am Acad Dermatol (2014) 71:468-74. doi: 10.1016/j.jaad.2014.04.053

39. Genovese G, Di Zenzo G, Cozzani E, Berti E, Cugno M, Marzano AV. New Insights Into the Pathogenesis of Bullous Pemphigoid: 2019 Update. Front Immunol (2019) 10:1506. doi: 10.3389/fimmu.2019.01506

40. Ameglio F, D'Auria L, Bonifati C, Ferraro C, Mastroianni A, Giacalone B. Cytokine Pattern in Blister Fluid and Serum of Patients With Bullous 
Pemphigoid: Relationships With Disease Intensity. Br J Dermatol (1998) 138:611-4. doi: 10.1046/j.1365-2133.1998.02169.x

41. Inaoki M, Takehara K. Increased Serum Levels of Interleukin (IL)-5, IL-6 and IL-8 in Bullous Pemphigoid. J Dermatol Sci (1998) 16:152-7. doi: 10.1016/s0923-1811(97)00044-3

42. Margaroli C, Bradley B, Thompson C, Brown MR, Giacalone VD, Bhatt L, et al. Distinct Compartmentalization of Immune Cells and Mediators Characterizes Bullous Pemphigoid Disease. Exp Dermatol (2020) 29:11918. doi: 10.1111/exd.14209

43. Suzuki M, Yamaguchi Y, Nakamura K, Kanaoka M, Matsukura S, Takahashi $\mathrm{K}$, et al. Serum Thymus and Activation-Regulated Chemokine (TARC/ CCL17) May Be Useful to Predict the Disease Activity in Patients With Bullous Pemphigoid. J Eur Acad Dermatol Venereol (2021) 35:e121-4. doi: $10.1111 /$ jdv.16851

44. Nakashima H, Fujimoto M, Asashima N, Watanabe R, Kuwano Y, Yazawa $\mathrm{N}$, et al. Serum Chemokine Profile in Patients With Bullous Pemphigoid. Br J Dermatol (2007) 156:454-9. doi: 10.1111/j.1365-2133.2006.07601.x

45. Kakinuma T, Wakugawa M, Nakamura K, Hino H, Matsushima K, Tamaki K. High Level of Thymus and Activation-Regulated Chemokine in Blister Fluid and Sera of Patients With Bullous Pemphigoid. $\mathrm{Br} J$ Dermatol (2003) 148:203-10. doi: 10.1046/j.1365-2133.2003.05066.x

46. Günther C, Carballido-Perrig N, Kopp T, Carballido JM, Pfeiffer C. CCL18 Is Expressed in Patients With Bullous Pemphigoid and Parallels Disease Course. Br J Dermatol (2009) 160:747-55. doi: 10.1111/j.1365-2133.2008.08979.x

47. Echigo T, Hasegawa M, Shimada Y, Inaoki M, Takehara K, Sato S. Both Th1 and Th2 Chemokines are Elevated in Sera of Patients With Autoimmune Blistering Diseases. Arch Dermatol Res (2006) 298:38-45. doi: 10.1007/ s00403-006-0661-5

48. Nin-Asai R, Muro Y, Sekiya A, Sugiura K, Akiyama M. Serum Thymus and Activation-Regulated Chemokine (TARC/CCL17) Levels Reflect the Disease Activity in a Patient With Bullous Pemphigoid. J Eur Acad Dermatol Venereol (2016) 30:327-8. doi: 10.1111/jdv.12719

49. Riani M, Le Jan S, Plée J, Durlach A, Le Naour R, Haegeman G, et al. Bullous Pemphigoid Outcome Is Associated With CXCL10-Induced Matrix Metalloproteinase 9 Secretion From Monocytes and Neutrophils But Not Lymphocytes. J Allergy Clin Immunol (2017) 139:863-72.e3. doi: 10.1016/ j.jaci.2016.08.012

50. Engineer L, Bhol K, Kumari S, Razzaque Ahmed A. Bullous Pemphigoid: Interaction of Interleukin 5, Anti-Basement Membrane Zone Antibodies and Eosinophils. A Preliminary Observation. Cytokine (2001) 13:32-8. doi: $10.1006 /$ cyto.2000.0791

51. D’Auria L, Pietravalle M, Mastroianni A, Ferraro C, Mussi A, Bonifati C, et al. IL-5 Levels in the Serum and Blister Fluid of Patients With Bullous Pemphigoid: Correlations With Eosinophil Cationic Protein, RANTES, IgE and Disease Severity. Arch Dermatol Res (1998) 290:25-7. doi: 10.1007/ s004030050272

52. Kagami S, Kai H, Kakinuma T, Miyagaki T, Kamata M, Sugaya M, et al. High Levels of CCL26 in Blister Fluid and Sera of Patients With Bullous Pemphigoid. J Invest Dermatol (2012) 132:249-51. doi: 10.1038/jid. 2011.251

53. Bernard P, Venot J, Constant F, Bonnetblanc JM. Blood Eosinophilia as a Severity Marker for Bullous Pemphigoid. J Am Acad Dermatol (1987) 16:879-81. doi: 10.1016/s0190-9622(87)80227-x

54. Farnaghi F, Ehsani AH, Kamyab-Hesary K, Abbasian S, Seirafi H, Nasimi M. Correlation of Dermal and Blood Eosinophilia With Bullous Pemphigoid Disease Severity. Int J Womens Dermatol (2020) 6:171-5. doi: 10.1016/ j.ijwd.2020.01.005

55. Kridin K. Peripheral Eosinophilia in Bullous Pemphigoid: Prevalence and Influence on the Clinical Manifestation. Br J Dermatol (2018) 179:1141-7. doi: $10.1111 /$ bjd.16679

56. Messingham KN, Holahan HM, Frydman AS, Fullenkamp C, Srikantha R, Fairley JA. Human Eosinophils Express the High Affinity IgE Receptor, FceRI, in Bullous Pemphigoid. PloS One (2014) 9:e107725. doi: 10.1371/ journal.pone.0107725

57. Marzano AV, Tedeschi A, Fanoni D, Bonanni E, Venegoni L, Berti E, et al. Activation of Blood Coagulation in Bullous Pemphigoid: Role of Eosinophils, and Local and Systemic Implications. Br J Dermatol (2009) 160:266-72. doi: 10.1111/j.1365-2133.2008.08880.x
58. Tedeschi A, Marzano AV, Lorini M, Balice Y, Cugno M. Eosinophil Cationic Protein Levels Parallel Coagulation Activation in the Blister Fluid of Patients With Bullous Pemphigoid. J Eur Acad Dermatol Venereol (2015) 29:813-7. doi: $10.1111 /$ jdv.12464

59. D’Auria L, Mussi A, Bonifati C, Mastroianni A, Giacalone B, Ameglio F. Increased Serum IL-6, TNF-Alpha and IL-10 Levels in Patients With Bullous Pemphigoid: Relationships With Disease Activity. J Eur Acad Dermatol Venereol (1999) 12:11-5. doi: 10.1111/j.1468-3083.1999. tb00801.x

60. Teraki Y, Hotta T, Shiohara T. Skin-Homing Interleukin-4 and -13Producing Cells Contribute to Bullous Pemphigoid: Remission of Disease Is Associated With Increased Frequency of Interleukin-10-Producing Cells. J Invest Dermatol (2001) 117:1097-102. doi: 10.1046/j.0022-202x. 2001.01505.x

61. Riani M, Muller C, Bour C, Bernard P, Antonicelli F, Le Jan S. Blister Fluid Induces MMP-9-Associated M2-Type Macrophages in Bullous Pemphigoid. Front Immunol (2019) 10:1858. doi: 10.3389/fimmu.2019.01858

62. Antiga E, Quaglino P, Volpi W, Pierini I, Del Bianco E, Bianchi B, et al. Regulatory T Cells in Skin Lesions and Blood of Patients With Bullous Pemphigoid. J Eur Acad Dermatol Venereol (2014) 28:222-30. doi: 10.1111/ jdv.12091

63. Asashima N, Fujimoto M, Watanabe R, Nakashima H, Yazawa N, Okochi H, et al. Serum Levels of BAFF Are Increased in Bullous Pemphigoid But Not in Pemphigus Vulgaris. Br J Dermatol (2006) 155:330-6. doi: 10.1111/j.13652133.2006.07305.x

64. Watanabe R, Ishiura N, Nakashima H, Yazawa N, Kuwano Y, Tada Y, et al. Increased Serum Levels of Circulating CD40 Ligand in Patients With Bullous Pemphigoid: Preliminary Results. Dermatology (2007) 215:180-6. doi: $10.1159 / 000106573$

65. Watanabe R, Fujimoto M, Yazawa N, Nakashima H, Asashima N, Kuwano $\mathrm{Y}$, et al. Increased Serum Levels of a Proliferation-Inducing Ligand in Patients With Bullous Pemphigoid. J Dermatol Sci (2007) 46:53-60. doi: 10.1016/j.jdermsci.2006.12.008

66. Fang H, Shao S, Cao T, Lei J, Dang E, Zhang J, et al. Increased Expression of NLRP3 Inflammasome Components and Interleukin-18 in Patients With Bullous Pemphigoid. J Dermatol Sci (2016) 83:116-23. doi: 10.1016/ j.jdermsci.2016.04.009

67. Li Q, Liu Z, Dang E, Jin L, He Z, Yang L, et al. Follicular Helper T Cells (Tfh) and IL-21 Involvement in the Pathogenesis of Bullous Pemphigoid. PloS One (2013) 8:e68145. doi: 10.1371/journal.pone.0068145

68. D’Auria L, Bonifati C, Cordiali-Fei P, Leone G, Picardo M, Pietravalle M, et al. Increased Serum Interleukin-15 Levels in Bullous Skin Diseases: Correlation With Disease Intensity. Arch Dermatol Res (1999) 291:354-6. doi: $10.1007 / \mathrm{s} 004030050421$

69. Plée J, Le Jan S, Giustiniani J, Barbe C, Joly P, Bedane C, et al. Integrating Longitudinal Serum IL-17 and IL-23 Follow-Up, Along With Autoantibodies Variation, Contributes to Predict Bullous Pemphigoid Outcome. Sci Rep (2015) 5:18001. doi: 10.1038/srep18001

70. Brulefert A, Le Jan S, Plée J, Durlach A, Bernard P, Antonicelli F, et al. Variation of the Epidermal Expression of Glucocorticoid Receptor-Beta as Potential Predictive Marker of Bullous Pemphigoid Outcome. Exp Dermatol (2017) 26:1261-6. doi: 10.1111/exd.13444

71. Czech W, Schaller J, Schöpf E, Kapp A. Granulocyte Activation in Bullous Diseases: Release of Granular Proteins in Bullous Pemphigoid and Pemphigus Vulgaris. J Am Acad Dermatol (1993) 29:210-5. doi: 10.1016/ 0190-9622(93)70170-x

72. Giusti D, Gatouillat G, Le Jan S, Plée J, Bernard P, Antonicelli F, et al. Eosinophil Cationic Protein (ECP), A Predictive Marker of Bullous Pemphigoid Severity and Outcome. Sci Rep (2017) 7:4833. doi: 10.1038/ s41598-017-04687-5

73. Marzano AV, Tedeschi A, Berti E, Fanoni D, Crosti C, Cugno M. Activation of Coagulation in Bullous Pemphigoid and Other Eosinophil-Related Inflammatory Skin Diseases. Clin Exp Immunol (2011) 165:44-50. doi: 10.1111/j.1365-2249.2011.04391.x

74. Deza G, Ricketti PA, Giménez-Arnau AM, Casale TB. Emerging Biomarkers and Therapeutic Pipelines for Chronic Spontaneous Urticaria. J Allergy Clin Immunol Pract (2018) 6:1108-17. doi: 10.1016/ j.jaip.2018.02.024 
75. Kushner CJ, Payne AS. Increasing the Complement of Therapeutic Options in Bullous Pemphigoid. J Invest Dermatol (2018) 138:246-8. doi: 10.1016/ j.jid.2017.09.026

76. Chiorean RM, Baican A, Mustafa MB, Lischka A, Leucuta DC, Feldrihan V, et al. Complement-Activating Capacity of Autoantibodies Correlates With Disease Activity in Bullous Pemphigoid Patients. Front Immunol (2018) 9:2687. doi: 10.3389/fimmu.2018.02687

77. Fang H, Zhang Y, Li N, Wang G, Liu Z. The Autoimmune Skin Disease Bullous Pemphigoid: The Role of Mast Cells in Autoantibody-Induced Tissue Injury. Front Immunol (2018) 9:407. doi: 10.3389/fimmu. 2018.00407

78. Bieber K, Ernst AL, Tukaj S, Holtsche MM, Schmidt E, Zillikens D, et al. Analysis of Serum Markers of Cellular Immune Activation in Patients With Bullous Pemphigoid. Exp Dermatol (2017) 26:1248-52. doi: 10.1111/ exd.13382

79. D'Auria L, Pietravalle M, Cordiali-Fei P, Ameglio F. Increased Tryptase and Myeloperoxidase Levels in Blister Fluids of Patients With Bullous Pemphigoid: Correlations With Cytokines, Adhesion Molecules and AntiBasement Membrane Zone Antibodies. Exp Dermatol (2000) 9:131-7. doi: 10.1034/j.1600-0625.2000.009002131.x

80. Qiu L, Zhang L, Qi R, Gao X, Chen H, Xiao T. miR-1291 Functions as a Potential Serum Biomarker for Bullous Pemphigoid. Dis Markers (2020) 2020:9505312. doi: 10.1155/2020/9505312

81. Amber KT, Maglie R, Solimani F, Eming R, Hertl M. Targeted Therapies for Autoimmune Bullous Diseases: Current Status. Drugs (2018) 78:1527-48. doi: 10.1007/s40265-018-0976-5

82. Murrell DF, Peña S, Joly P, Marinovic B, Hashimoto T, Diaz LA, et al. Diagnosis and Management of Pemphigus: Recommendations of an International Panel of Experts. J Am Acad Dermatol (2020) 82:575-85.e1. doi: 10.1016/j.jaad.2018.02.021

83. Cho YT, Chu CY, Wang LF. First-Line Combination Therapy With Rituximab and Corticosteroids Provides a High Complete Remission Rate in Moderate-to-Severe Bullous Pemphigoid. Br J Dermatol (2015) 173:3024. doi: 10.1111/bjd.13633

84. Chee R, Nagendran V, Bansal A, Casie Chetty SN, Harland C. B-Cell Targeted Therapy Alone May Not Be Effective in Bullous Pemphigoid. Clin Exp Dermatol (2007) 32:111-2. doi: 10.1111/j.1365-2230. 2006.02267.x

85. Hall RP 3rd, Streilein RD, Hannah DL, McNair PD, Fairley JA, Ronaghy A, et al. Association of Serum B-Cell Activating Factor Level and Proportion of Memory and Transitional B Cells With Clinical Response After Rituximab Treatment of Bullous Pemphigoid Patients. J Invest Dermatol (2013) 133:2786-8. doi: 10.1038/jid.2013.236

86. Schmidt E, Seitz CS, Benoit S, Bröcker EB, Goebeler M. Rituximab in Autoimmune Bullous Diseases: Mixed Responses and Adverse Effects. $\mathrm{Br} \mathrm{J}$ Dermatol (2007) 156:352-6. doi: 10.1111/j.1365-2133.2006.07646.x

87. Adler BL, Crew AB, Woodley DT. Early-Onset Neutropenia After Rituximab Therapy for Bullous Pemphigoid. Clin Exp Dermatol (2019) 44:334-6. doi: 10.1111/ced.13726

88. Schmidt E, Hunzelmann N, Zillikens D, Bröcker EB, Goebeler M. Rituximab in Refractory Autoimmune Bullous Diseases. Clin Exp Dermatol (2006) 31:503-8. doi: 10.1111/j.1365-2230.2006.02151.x

89. Ahmed AR, Shetty S, Kaveri S, Spigelman ZS. Treatment of Recalcitrant Bullous Pemphigoid (BP) With a Novel Protocol: A Retrospective Study With a 6-Year Follow-Up. J Am Acad Dermatol (2016) 74:700-8.e3. doi: 10.1016/j.jaad.2015.11.030

90. Fairley JA, Baum CL, Brandt DS, Messingham KA. Pathogenicity of IgE in Autoimmunity: Successful Treatment of Bullous Pemphigoid With Omalizumab. J Allergy Clin Immunol (2009) 123:704-5. doi: 10.1016/ j.jaci.2008.11.035

91. Maglie R, Antiga E, Quintarelli L, Verdelli A, Caproni M. Dramatic Exacerbation of Bullous Pemphigoid Following Rituximab and Successful Treatment With Omalizumab. Eur J Dermatol (2019) 29:213-5. doi: 10.1684/ejd.2019.3499

92. Lonowski S, Sachsman S, Patel N, Truong A, Holland V. Increasing Evidence for Omalizumab in the Treatment of Bullous Pemphigoid. JAAD Case Rep (2020) 6:228-33. doi: 10.1016/j.jdcr.2020.01.002

93. Vico-Alonso C, Calleja-Algarra A, Aragón-Miguel R, Sánchez-Velázquez A, Velasco-Tamariz V, Ortiz-Romero PL, et al. Omalizumab as an Alternative
Therapeutic Tool in the Treatment of Bullous Pemphigoid: A Case Report. Dermatol Ther (2019) 32:e12829. doi: 10.1111/dth.12829

94. Menzinger S, Kaya G, Schmidt E, Fontao L, Laffitte E. Biological and Clinical Response to Omalizumab in a Patient With Bullous Pemphigoid. Acta Derm Venereol (2018) 98:284-6. doi: 10.2340/00015555-2845

95. Balakirski G, Alkhateeb A, Merk HF, Leverkus M, Megahed M. Successful Treatment of Bullous Pemphigoid With Omalizumab as CorticosteroidSparing Agent: Report of Two Cases and Review of Literature. J Eur Acad Dermatol Venereol (2016) 30:1778-82. doi: 10.1111/jdv.13758

96. London VA, Kim GH, Fairley JA, Woodley DT. Successful Treatment of Bullous Pemphigoid With Omalizumab. Arch Dermatol (2012) 148:1241-3. doi: 10.1001/archdermatol.2012.1604

97. Navarro-Triviño FJ, Llamas-Molina JM, Ayen-Rodriguez A, Cancela-Díez B, Ruiz-Villaverde R. Dramatic Improvement of Bullous Pemphigoid With Omalizumab in an Elderly Patient. Eur J Hosp Pharm (2020) 0:1-3. doi: 10.1136/ejhpharm-2020-002418

98. Sinha S, Agrawal D, Sardana K, Kulhari A, Malhotra P. Complete Remission in a Patient With Treatment Refractory Bullous Pemphigoid After a Single Dose of Omalizumab. Indian Dermatol Online J (2020) 11:607-11. doi: 10.4103/idoj.IDOJ_438_19

99. Seyed Jafari SM, Gadaldi K, Feldmeyer L, Yawalkar N, Borradori L, Schlapbach C. Effects of Omalizumab on FceRI and IgE Expression in Lesional Skin of Bullous Pemphigoid. Front Immunol (2019) 10:1919. doi: 10.3389/fimmu.2019.01919

100. Garrido PM, Alexandre MI, Travassos AR, Filipe P. Dipeptidyl-Peptidase IV Inhibitor-Associated Bullous Pemphigoid Efficiently Treated With Omalizumab. Dermatol Ther (2020) 33:e14160. doi: 10.1111/dth.14160

101. Seyed Jafari SM, Feldmeyer L, Bossart S, Simon D, Schlapbach C, Borradori L. Case Report: Combination of Omalizumab and Dupilumab for Recalcitrant Bullous Pemphigoid. Front Immunol (2020) 11:611549. doi: 10.3389/fimmu.2020.611549

102. Sarrazin M, Jouen F, Duvert-Lehembre S. Refractory Bullous Pemphigoid With IgE Anti-BP230 and IgG Anti-P200 Antibodies Successfully Treated With Omalizumab. Ann Dermatol Venereol (2021) 148:60-2. doi: 10.1016/ j.annder.2020.08.053

103. Freire PC, Muñoz CH, Derhaschnig U, Schoergenhofer C, Firbas C, Parry GC, et al. Specific Inhibition of the Classical Complement Pathway Prevents C3 Deposition along the Dermal-Epidermal Junction in Bullous Pemphigoid. J Invest Dermatol (2019) 139:2417-24.e2. doi: 10.1016/ j.jid.2019.04.025

104. Karsten CM, Beckmann T, Holtsche MM, Tillmann J, Tofern S, Schulze FS, et al. Tissue Destruction in Bullous Pemphigoid Can Be Complement Independent and May Be Mitigated by C5aR2. Front Immunol (2018) 9:488. doi: 10.3389/fimmu.2018.00488

105. Kaye A, Gordon SC, Deverapalli SC, Her MJ, Rosmarin D. Dupilumab for the Treatment of Recalcitrant Bullous Pemphigoid. JAMA Dermatol (2018) 154:1225-6. doi: 10.1001/jamadermatol.2018.2526

106. Seidman JS, Eichenfield DZ, Orme CM. Dupilumab for Bullous Pemphigoid With Intractable Pruritus. Dermatol Online J (2019) 25(11):130130/ qt25q9w6r9. doi: 10.5070/D32511046147

107. Abdat R, Waldman RA, de Bedout V, Czernik A, McLeod M, King B, et al. Dupilumab as a Novel Therapy for Bullous Pemphigoid: A Multicenter Case Series. J Am Acad Dermatol (2020) 83:46-52. doi: 10.1016/ j.jaad.2020.01.089

108. Erichsen CY, Jensen P, Kofoed K. Biologic Therapies Targeting the Interleukin (IL)-23/IL-17 Immune Axis for the Treatment of Moderate-toSevere Plaque Psoriasis: A Systematic Review and Meta-Analysis. J Eur Acad Dermatol Venereol (2020) 34:30-8. doi: 10.1111/jdv.15879

109. Armstrong AW, Read C. Pathophysiology, Clinical Presentation, and Treatment of Psoriasis: A Review. Jama (2020) 323:1945-60. doi: 10.1001/ jama.2020.4006

110. Monshi B, Gulz L, Piringer B, Wiala A, Kivaranovic D, Schmidt M, et al. Anti-BP180 Autoantibody Levels at Diagnosis Correlate With 1-Year Mortality Rates in Patients With Bullous Pemphigoid. J Eur Acad Dermatol Venereol (2020) 34:1583-9. doi: 10.1111/jdv.16363

111. Joly P, Roujeau JC, Benichou J, Picard C, Dreno B, Delaporte E, et al. A Comparison of Oral and Topical Corticosteroids in Patients With Bullous Pemphigoid. N Engl J Med (2002) 346:321-7. doi: 10.1056/NEJMoa011592 
112. Roujeau JC, Lok C, Bastuji-Garin S, Mhalla S, Enginger V, Bernard P. High Risk of Death in Elderly Patients With Extensive Bullous Pemphigoid. Arch Dermatol (1998) 134:465-9. doi: 10.1001/archderm.134.4.465

113. Joly P, Benichou J, Lok C, Hellot MF, Saiag P, Tancrede-Bohin E, et al. Prediction of Survival for Patients With Bullous Pemphigoid: A Prospective Study. Arch Dermatol (2005) 141:691-8. doi: 10.1001/archderm.141.6.691

114. Rozenblat M, Halaj A, Rozenblat T, Fisher S, Sah M, Dodiuk-Gad RP, et al. Mortality and Risk Factors Among Israeli Bullous Pemphigoid Patients. Arch Dermatol Res (2019) 311:19-27. doi: 10.1007/s00403-018-1875-z

115. Liu YD, Wang YH, Ye YC, Zhao WL, Li L. Prognostic Factors for Mortality in Patients With Bullous Pemphigoid: A Meta-Analysis. Arch Dermatol Res (2017) 309:335-47. doi: 10.1007/s00403-017-1736-1

116. Cai SC, Allen JC, Lim YL, Chua SH, Tan SH, Tang MB. Mortality of Bullous Pemphigoid in Singapore: Risk Factors and Causes of Death in 359 Patients Seen at the National Skin Centre. Br J Dermatol (2014) 170:1319-26. doi: $10.1111 /$ bjd.12806
Conflict of Interest: The authors declare that the research was conducted in the absence of any commercial or financial relationships that could be construed as a potential conflict of interest.

Publisher's Note: All claims expressed in this article are solely those of the authors and do not necessarily represent those of their affiliated organizations, or those of the publisher, the editors and the reviewers. Any product that may be evaluated in this article, or claim that may be made by its manufacturer, is not guaranteed or endorsed by the publisher.

Copyright $\odot 2021$ Zhou, Peng and Geng. This is an open-access article distributed under the terms of the Creative Commons Attribution License (CC BY). The use, distribution or reproduction in other forums is permitted, provided the original author(s) and the copyright owner(s) are credited and that the original publication in this journal is cited, in accordance with accepted academic practice. No use, distribution or reproduction is permitted which does not comply with these terms. 